\title{
The establishment of a sustainable management policy for coastal foraging (Oléron, France)
}

\author{
G. Mossot \& V. Duvat \\ Department of Geography, Institute of Littoral and Environment, \\ La Rochelle University, France
}

\begin{abstract}
Geographical studies have developed in recent years that involve the qualification of tourism and leisure practices in order to understand their intrinsic standards and values, usefully supplementing the quantitative work of biologists. Using the example of recreational coastal foraging on Oléron Island, this article highlights the importance of the development of a forager typology to improve understanding of their impact on the resource, and to support the implementation of a sustainable management policy for the foreshore. The GIPREOL (Integrated Management of Recreational Practices on the Foreshore: the example of coastal foraging on Oléron Island) research programme, the first results of which are presented in this article, takes into account all the dimensions of this touristic and recreational practice, including ecological, socioeconomic and legal factors. Its multidisciplinary nature should enable it to bring operational solutions to the authorities currently involved in the implementation of the "Oléron Coastal Quality" policy.
\end{abstract}

Keywords: sustainability, integrated coastal zone management, management support, recreational coastal foraging, Oléron Island, France.

\section{Introduction}

Taking recreational fishing practices into consideration within policies for integrated coastal zone management is a very recent development.

The first research into recreational angling originated in Australia in the 1990s and looked at sea fishing from boats with lines. They focused on the resource, aiming to quantify the impact of predation by humans in order to 
reduce it [1]. The growth in leisure and tourism practices has led to the emergence of work aimed at the analysis of the relationship between humans and their environment $[2,3]$. Since the early 2000s, research on recreational fishing has been enhanced with studies into frequentation, some of which incorporate the concept of carrying capacity [4-6]. The creation of marine parks and reserves, together with the establishment of observatories, has also favoured this development. Today, in the context of policy implementation for integrated coastal zone management, the authorities are seeking comprehensive analyses with particular emphasis on the extensive investigation into practices.

The implementation of a sustainable management policy for coastal foraging on Oléron island (20991 inhabitants in 2006, $175 \mathrm{~km}^{2}$ ), on the French Atlantic coast, lies within this context. The construction of a bridge in 1966 that linked Oléron to the mainland was the origin of a boom in tourism (a doubling of the summer population) and leisure (the arrival of day-trippers), which have significantly contributed towards an increase in coastal foraging. Recent studies by the IODDE (Ile d'Oléron Sustainable Development Environment) Association estimate the number of fishing trips conducted between January and September 2007 to be 130,000. The annual catch is around 330 tonnes of all species [7-9]. Since 2005, the Pays Marennes Oléron (which includes the group of municipalities of Oléron Island and that of the continental basin of Marennes) has embarked on a project of Integrated Coastal Zone Management which resulted in the implementation of the "Oléron Coastal Quality" project in 2007. The objective is to establish a comprehensive management plan for the coast that combines socioeconomic objectives (improvement of user hospitality, development of tourism and leisure activities, maintenance of employment) and environmental (protection of areas, especially beaches and foreshores with high biodiversity). A key strategic direction that has been undertaken to achieve these objectives is the improvement of the organization and administration of touristic and leisure activities, including coastal foraging.

This article presents the first results of the Geography component of the GIPREOL research programme (Integrated Management of Recreational Practices on the Foreshore: the example of coastal foraging on Oléron island), carried out in close partnership with the Pays Marennes Oléron and the Communauté de Communes de l'île d'Oléron. We firstly describe the structure of this research programme and the role and content of its geographical approach. The second section of the article examines the results of a 2009 survey conducted amongst coastal foragers and presents a typology of foragers that the survey has established. The value of this study for the implementation of the sustainable management policy for coastal resources, which is desired by the local stakeholders, will be identified and discussed in the conclusion.

\section{The GIPREOL multidisciplinary research programme}

\subsection{GIPREOL programme overview}

The research programme "Integrated Management of Recreational Practices on the Foreshore: the example of coastal foraging on Oléron island" (GIPREOL) is 
supported by the French National Research Agency (ANR SYSTERRA programme). It is part of a multidisciplinary approach involving biologists, lawyers and geographers. It is also a multi-partner scheme, which brings together scientists, managers and an NGO. Its purpose is to characterize the pressure on a particular crab species, the velvet swimming crab (Necora puber), caused by coastal foraging, as well as the disturbance to the ecosystem generated through this practice. Its main objective is to contribute to the implementation of an integrated and sustainable management plan for the coastal resources of Oléron Island.

This is a three-year programme (2009 to 2011) for which each year corresponds to a particular phase of the study. The first year involved the preparation of an inventory of the resource, the practice of foraging, the management system and the regulations. The second year, currently underway, is a phase of action and in situ experimentation. The aim is, firstly, to measure the responses of the target species to different levels of fishing pressure, and secondly, to test the efficiency of various methods of raising public awareness. The final year will be dedicated to the assessment of the results obtained. If management measures applied to experimental pilot sites provide satisfactory results, these measures will be implemented on a wider scale.

Two pilot sites were selected for the programme; one is located on the island's western coast (Saint-Denis d'Oléron), and the other on its eastern shore (Brée-les-Bains) (Fig. 1). Although these sites have different physical characteristics, they are both favourable for the development of velvet swimming crab populations and are regularly frequented by coastal foragers. The site of Brée-les-Bains is located on the island's sheltered coast, adjacent to the village that shares the same name. The site, which is bordered by a sandy beach, alternates between rocky outcrops and sandy deposits as it extends towards the sea (Fig. 2). The rocky foreshore of Saint-Denis d'Oléron is remote from villages and subject to heavy sea swells. Adjoining a pebble beach that borders a

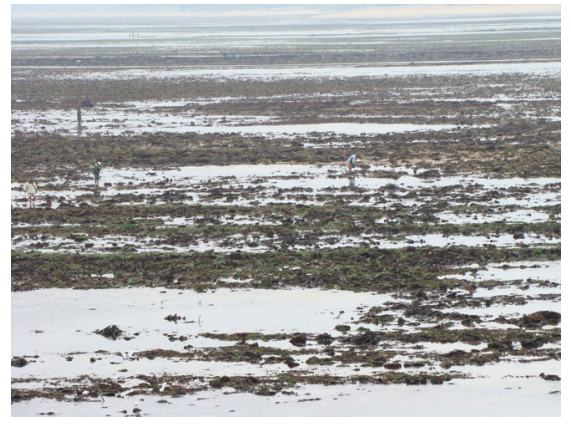

Figure 1: Rocky outcrops of the La Figure 2 Brée-les-Bains foreshore.

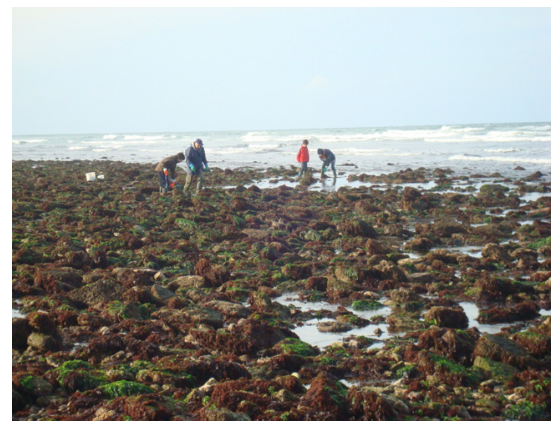

Boulder fields of the rocky foreshore of SaintDenis d'Oléron. 


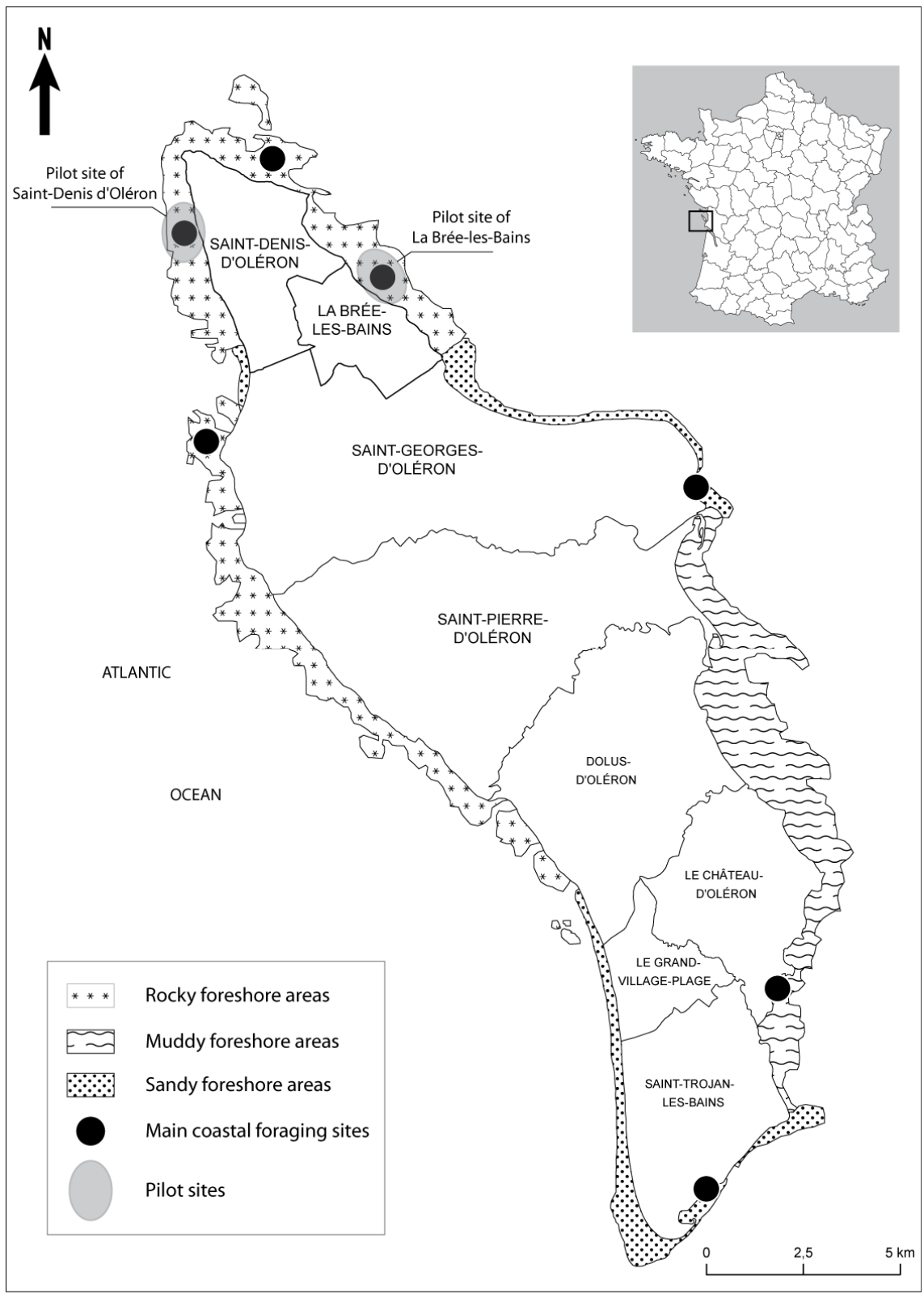

Figure 3: Location and characteristics of Oléron Island's coastal foraging sites. 
limestone cliff, the site extends over several hundred meters (Fig. 3). Due to differences in location, exposure and morphology, these two foreshore areas can attract foragers with distinct profiles.

\subsection{The contribution of geography in the GIPREOL programme}

The Geography component of the GIPREOL programme aims to contribute towards the implementation of an integrated and sustainable management plan for Oléron's coastal resources, from the production of data on the practice of coastal foraging and its management, to the distribution of such information among foragers as well as policymakers and administrators. Each of its three years corresponds to a specific step.

The first year was dedicated to the analysis of the stakeholder system, which includes the "practitioners" and "authorities" components (Fig. 4). The approach developed should enable the following questions to be answered: Who are the foragers? Who are the stakeholders involved in the management of coastal foraging? What are the strengths and weaknesses of the area for the implementation of integrated and sustainable foraging?

Regarding the practice of foraging, two lines of research were developed. The first involved the compilation of a coastal foraging inventory that is both

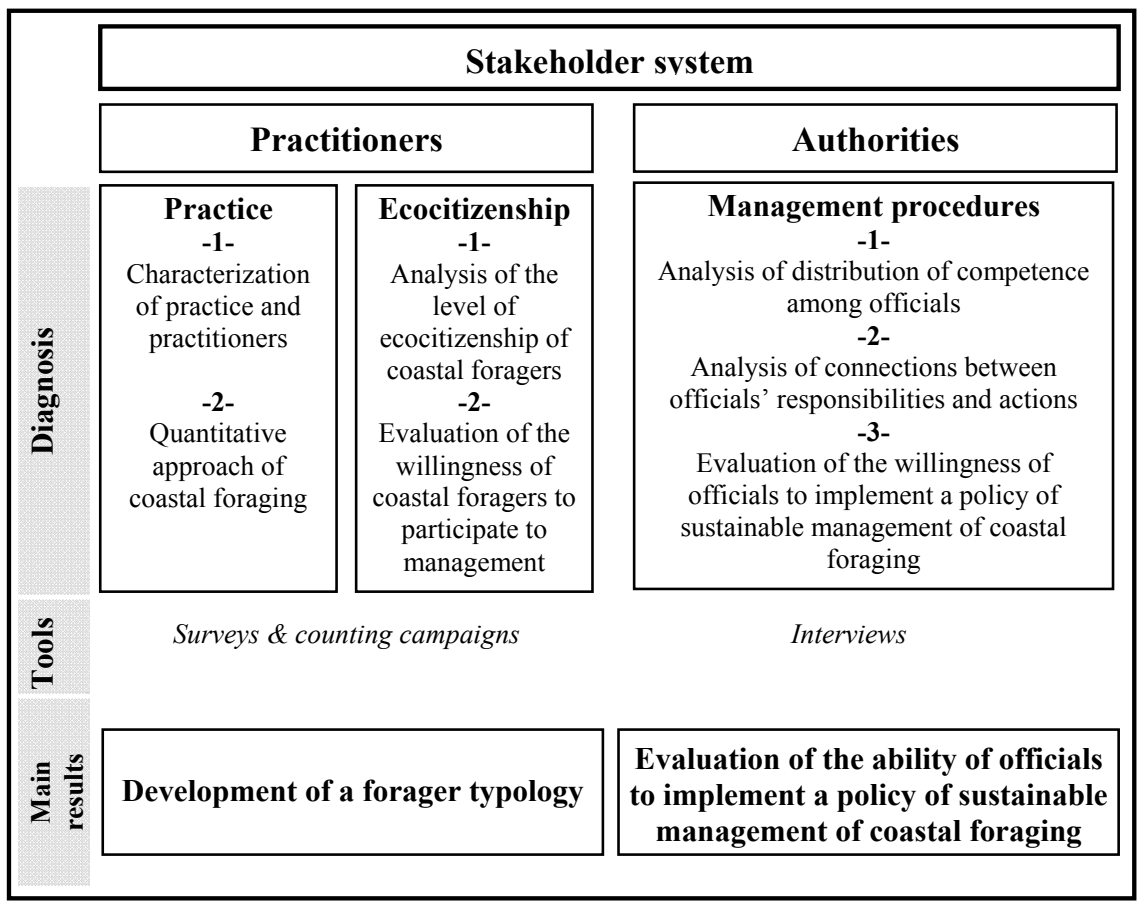

Figure 4: Presentation of the scientific procedure followed to analyze the stakeholder system (GIPREOL research programme). 
qualitative (identification of foragers, valuation of the practice, the experience of practitioners, their knowledge of the environment and the species in question, and their relationship with the foreshore...) and quantitative (visitor pressure on the foreshore). The second line of research aimed to assess, firstly, the "ecocitizenship" of practitioners, and also their willingness to participate in a policy of sustainably-managed foraging (the level of interest shown by foragers towards this approach, their ability to modify their practices and to become mobilized). Within the framework of this study, eco-citizenship is defined as the implementation of simple rules to respect the environment: replacing rocks that have been turned, releasing berried female crabs and those that are undersized, and taking action when observing foragers that do not comply with these best practices. The main objective of this approach was to develop an initial typology of coastal foragers, which is presented in this article.

Regarding management procedures, the intention was to examine the distribution of competence among officials, as well as the connections between their responsibilities and their actions, the aim being to evaluate their willingness and ability to implement a policy of sustainable and integrated management of coastal foraging.

The second year will be an experimentation phase. On the basis of the results obtained, actions will commence to strengthen the capacity of stakeholders to sustainably manage coastal foraging. The primary mode of intervention will be the provision of information and raising the awareness of practitioners.

In the third year, evaluation of the expansion of good foraging techniques will allow the efficiency of actions implemented during the second year to be measured. It is also planned to apply the work carried out and to share it with other areas with similar experiences or management needs.

\section{Methods and results}

The main method used was the survey, coupled with systematic field observations.

\subsection{Survey methodology}

The survey questionnaire was developed in close collaboration with ecologists and lawyers from the GIPREOL programme with several objectives in mind: (1) to benefit from the knowledge of ecologists who, similarly to the IODDE association, have conducted research on the foreshore for several years; (2) to integrate specific questions relating to other disciplines involved in this programme; (3) to develop a collective thought process going from the design of the survey to the interpretation of results.

Due to the weakness of the qualitative knowledge available on the practice of coastal foraging, and also because of the relatively wide scope to be covered in the survey, it was decided to focus on a qualitative approach that involved sampling a relatively limited number of foragers (around 50) with a large number of questions (132 in total). Given that visitor numbers to the foreshore (a 
few tens of foragers maximum per fishing session outside the tourist season) and the loyalty of foragers to their fishing sites (high fidelity rate), the results produced are very representative.

The survey was administered directly to the foragers in two stages. The first part was conducted on site during a fishing session. In order not to take up too much fishing time (one session lasts about an hour and a half), it was decided to do the second part of the questionnaire by telephone. This procedure worked very well. Of the 53 completed questionnaires, 32 were obtained from SaintDenis d'Oleron between March and May 2009; and 21 from La Brée-les-Bains during the spring tides of July 2009. The chosen dates, which were two different periods including a summer holiday, enabled tourists and owners of secondary residences to be incorporated into the study.

\subsection{Typical profile of the "traditional" forager}

Coastal foraging is an ancestral practice that has endured through the centuries. Its status has recently changed from that of a subsistence activity to one of recreation and tourism. Recent developments, which will be expanded upon in the next paragraph, do not affect the cultural heritage value of the practice that frequent foragers cite as important. The mode of transmission of foraging methods, the tools used and the forager's commitment to his "fishing spot" clearly reflect the strong grounding of this activity both in time ("traditional" importance) and place (high territorialization of the foreshore).

Observations and investigations undertaken outside of the touristic season have enabled the typical "traditional" forager profile to be assembled, which reflects well the permanence of the relationship between past and present. A representative of this forager group would be a mature male, originally from a coastal region, who practices this activity on his own and has generally done so for at least 25 years. His expertise is inherited from his ancestors. He considers the foreshore to be an area of freedom, relaxation and recreation. This is an open space that allows him to overcome the constraints of daily life. The foreshore is an area that he understands thoroughly; he knows its precise morphology, its species and its dimensions.

\subsection{The first typology of coastal foragers}

The aim was to classify the foragers according to their relationship with the area (frequency of foraging, knowledge of the foreshore, impact of the activity, willingness to participate in the implementation of sustainable foraging). Thus, the criterion "knowledge of the locality and the ecological impact of the practitioner" was chosen as the structural basis for the development of the following typology. This classification is also based on other criteria, which aim to clarify the relationship with the environment, and the level of impact of the forager on the resource: forager status (permanent or temporary resident, tourist, day-tripper), foraging education, foraging procedures and associated values, sense of custodianship over the foreshore, and level of eco-citizenship. 
This typology highlights the wide variety of practitioner profiles that have resulted from recent developments, particularly the increase of touristic and recreational foraging.

\section{Group 1: local, experienced and eco-citizen foragers (11\%)}

This category corresponds to the so-called "traditional" foragers.

Foraging education: these foragers live in the region throughout the year and have been foraging for over 25 years. $83 \%$ of this group come from a fisherman family and $66 \%$ learnt how to collect shellfish from their parents. They obtain excellent yields (more than 20 velvet swimmer crabs per outing), understand the life cycle of the species, and know which months are best for collecting.

Foraging procedures and associated values: these foragers go out all year, except during July and August, and particularly during the equinoctial spring tides. They make preparations at least two days in advance and are equipped with professional equipment (waders, hook, net and traditional Gourbeille basket).

Sense of custodianship over the foreshore: these foragers have their own "fishing spots", the foreshore being a real practice territory.

Eco-citizenship: these foragers are aware of the high biodiversity of the foreshore. They practice environmentally friendly foraging, replacing rocks that they turn and releasing berried females and undersized crabs. They sometimes intervene when observing less experienced practitioners, to teach them about good practices. These foragers would be willing if asked to modify their techniques to improve species regeneration. $83 \%$ would like to be involved in the management of foraging.

\section{Group 2: "responsible" frequent foragers $(35.8 \%)$}

Foraging education: more than three-quarters of the foragers within this category live in a coastal region. 52\% have foraged for more than 25 years and come from a fisherman family. One third have learned foraging methods from their parents. These foragers obtain lower yields than the previous group, collecting between 6 and 20 crabs per outing, which is due to the fact that they are unaware of the life cycle of the species. This group includes day-trippers and owners of secondary residences who are less familiar with the area than those in Group 1.

Foraging procedures and associated values: these foragers come to Oléron, not only to fish but also to enjoy their second home and/or more generally the island itself. They forage throughout the year, but do so on a regular basis only in spring. They make few preparations for their fishing expeditions. 68\% are well equipped.

Sense of custodianship over the foreshore: $84 \%$ of this group have a preferential fishing area. They know the foreshore well and feel a level of custodianship.

Eco-citizenship: These foragers know that the rocky foreshore is rich environment. The majority of the group release buried females, and would be willing to change their practices to improve species preservation. They do not live on the island and do not wish to participate in the management of foraging. However, they are receptive to information. 


\section{Group 3: "ill-informed" frequent foragers (5.6\%)}

Foraging education: these foragers live in a coastal area and have foraged for over 25 years, during holiday periods. In general, they have learnt foraging techniques through the family. Their fishing yield is relatively low (not more than 5 crabs per trip), which reflects their poor knowledge of the life cycle of the species and the fact that they have less expertise in foraging techniques than the previous groups.

Foraging procedures and associated values: this group engages in foraging throughout the year. Fishing is an important part of their summer holiday. They prepare for their foraging trip at least two days in advance and have suitable equipment.

Sense of custodianship over the foreshore: these regular tourists have their preferred fishing areas, but are less familiar with the foreshore than the foragers in the previous categories.

Eco-citizenship: these foragers are ill-informed about the environment, underestimating the biological richness of the area, and also regarding the species in question. For example, they do not recognize berried females. Consequently, their impact on the species is higher than that of the foragers of the previous categories. However, they say that they are ready to change their practices to reduce the impact that they have on the environment. None of the foragers in this category felt concerned enough about foraging to consider participating in its management.

\section{Group 4: opportunistic foragers $(22 \%)$}

Foraging education: these foragers live in coastal regions, two thirds come from a fisherman family and one third learnt to fish through their family. 58\% have foraged for over 25 years. They visit Oléron for day trips or for longer holidays. They obtain low yields, two thirds of them collecting 3 crabs per outing. They are unfamiliar with the life cycle of the species in question.

Foraging procedures and associated values: these foragers come to Oléron to meet friends or family, or to enjoy the environment. Foraging is part of their recreation, and they practice the activity mainly from April to October. They forage for pleasure and in a fairly opportunistic manner, $40 \%$ do not prepare for their outing and $25 \%$ are not equipped. For $60 \%$ of them, the trip provides an opportunity to walk or picnic.

Sense of custodianship over the foreshore: while they are regular visitors to Oléron Island, these foragers do not have a preferred fishing spot. Their criteria for selecting a fishing site are its proximity to their place of residence, its physical accessibility, and the quality of the surrounding landscape.

Eco-citizenship: these foragers are not aware of the richness of the rocky foreshore. They would however be willing to change their foraging methods to improve the preservation of biodiversity. $75 \%$ of them do not want to be involved in foraging management, partly because they do not live there. 


\section{Group 5: amateur foragers (24.5\%)}

Foraging education: these foragers are in Oléron as tourists but they originate from a coastal area and half of them come from a fisherman family. These foragers do not achieve a good yield; they visit the foreshore for walking and to discover the area's species. One third return without any catch at all, which can be explained by a lack of knowledge of the life cycle of the studied species and of the best months in which to find it.

Foraging procedures and associated values: two thirds only forage on Oléron, but only one third regularly visit the foreshore. Foraging is a secondary activity for these tourists, who practice from May to October, and during the summer holidays in particular. The foraging outing is usually improvised, $70 \%$ deciding to make the trip the day before or on the day itself, and $61 \%$ do not own the required equipment.

Sense of custodianship over the foreshore: only a quarter of these irregular foragers have a preferred fishing area.

Eco-citizenship: $40 \%$ of these foragers mistakenly believe that the rocky foreshore is a poor environment. They would be willing to modify their behaviour to improve species preservation. 50\% say that they release the berried females. A majority of these foragers would like to have more information about the environment and fishing techniques.

\section{Conclusion and perspectives}

Firstly, this study has shown that coastal foraging on rocky foreshores is a difficult activity that cannot be improvised. Foragers tend to originate from coastal regions and a majority come from fisherman families. Foraging for the velvet swimming crab is a custom that is passed from one generation to another, and requires technical expertise. This certainly explains why the "traditional" forager remains well represented on this type of foreshore, which he frequents throughout the year, despite the recent growth in forager numbers and the diversification of their profiles. At the two extremes of the typology proposed here are: local coastal foragers, who combine experience and respect for the environment; and the amateur and opportunistic foragers, who are mainly tourists that fish for pleasure as and when the opportunity arises. Day-trippers, who live in the region and make short foraging excursions to Oléron, are spread between these two categories. Understandably there is a strong relationship between a forager's place of residence (on or off the island, by the sea or not) and also their relationship to the foreshore (sense of custodianship, knowledge...).

The observation that opportunistic and amateur foragers, and more generally tourists, obtain a low catch raises the question of the significance of their impact on the resource. They catch few crabs and are only present on the foreshore during certain times of year. Is it possible that this group could have a greater impact on the environment (by turning over rocks) and on this crab species than experienced foragers, who fish throughout the whole year? To enable this 
question to be answered the implementation of regular survey campaigns would be very beneficial, allowing the determination of the precise proportion of each forager category within the total. In a second step, comparing quantitative data collected by biologists on the impact of coastal foraging with qualitative survey data would allow the determination of which forager categories have the strongest impact.

Finally, this study has shown that foragers are curious, they are interested in the environment and willing to access more knowledge and practical information. They are usually willing to change their practices (gathering techniques and collection sites) in order to better preserve the biodiversity of the foreshore. These elements constitute a number of favourable conditions for the implementation of the sustainable development policy for coastal foraging that is wanted by the authorities of Oléron Island.

\section{References}

[1] Kingsford, M.J. \& Underwood, A.J. \& Kennelly, S.J., Humans as predators on rocky reefs in New South Wales, Australia. Marine Ecology Progress Series, 72, pp. 1-14, 1991.

[2] Diegues, A.C., Environmental impact assessment: the point of view of artisanal fishermen communities in Brazil. Ocean and Coastal Management, 39, pp. 119-133, 1998.

[3] Papinot, C., Requalifications du littoral et conflits d'usage: l'estranenvironnement et l'estran-territoire. Sociétés Contemporaines, 52, pp. 105$121,2003$.

[4] VivArmor Nature, Projet de Contrat Nature Gestion durable de l'activité récréative de pêche à pied et préservation de la biodiversité littorale, $11 \mathrm{p}$, 2007.

[5] Delisle F., 2004, Gestion de la fréquentation pour la conservation des habitats et des espèces sur l'îlot du Verdelet: site Natura 2000 de la baie de Saint-Brieuc, DESS "Activités et aménagements littoraux et maritimes", Université de Montpellier, $102 \mathrm{p}$.

[6] Le Berre, S., Les observatoires de la fréquentation, outils d'aide à la décision des îles et des littoraux. Thèse de doctorat de géographie. Université de Bretagne Occidentale, 816 p., 2008.

[7] Île d'Oléron Développement Durable (IODDE), La pêche à pied récréative sur Oléron, programme REVE 2006 - 2009, rapport intermédiaire de diagnostic, 80 p, 2006.

[8] Île d'Oléron Développement Durable (IODDE), La pêche à pied récréative sur Oléron, programme REVE 2006 - 2009, second rapport intermédiaire de diagnostic, 118 p., 2007.

[9] Île d'Oléron Développement Durable (IODDE), La pêche à pied récréative sur Oléron, programme REVE 2006 - 2009, rapport de diagnostic, 65 p., 2008 . 